\title{
RESPOSTA DE PORTA-ENXERTOS DE CARAMBOLEIRA À ADUBAÇÃO COM ZINCO ${ }^{1}$
}

\author{
ANTONIO JOÃO DE LIMA NETO², WILLIAM NATALE ${ }^{3}$, VIVIANE CRISTINA MODESTO 4
}

RESUMO - Apesar de ser amplamente cultivada no Estado de São Paulo, na literatura, há poucas informações sobre os efeitos da adubação e da nutrição em porta-enxertos de caramboleira. O trabalho teve como objetivo avaliar o crescimento das plantas e o acúmulo de $\mathrm{Zn}$ em porta-enxertos de caramboleira, submetidos a diferentes doses de zinco. O trabalho foi desenvolvido entre os meses de setembro de 2012 e fevereiro de 2013, em viveiro comercial de produção de mudas, localizado em Taquaritinga-SP. O delineamento foi em blocos casualizados, com cinco doses de zinco: zero; 2,0; 4,0; 6,0 e 8,0 $\mathrm{mg} \mathrm{dm}^{-3}$ de Zn, quatro repetições e três plantas por parcela. Os porta-enxertos empregados no experimento estavam com um ano e dois meses de idade e foram cultivados em sacos de polietileno, com casca de pínus como substrato. Aos 170 dias após a aplicação do zinco, avaliaram-se: altura das plantas, diâmetro do caule, número de folhas, massa seca da parte aérea, das raízes e total. A concentração de zinco nas raízes e na parte aérea foi determinada e, em seguida, calculou-se o acúmulo de Zn nas diferentes partes da planta. O zinco influenciou na altura de plantas, diâmetro caulinar, emissão de folhas, acúmulo de massa seca da parte aérea, raízes e total. O maior desenvolvimento dos porta-enxertos de caramboleira esteve associado à dose entre 3,1 e $3,8 \mathrm{mg} \mathrm{dm}^{-3} \mathrm{de}$ $\mathrm{Zn}$. Doses elevadas de zinco prejudicam o crescimento e o acúmulo do micronutriente nos porta-enxertos de caramboleira.

Termos para indexação: Averrhoa carambola L., micronutriente, nutrição mineral.

\section{ROOTSTOCKS TO FERTILIZATION WITH ZINC}

\begin{abstract}
Even though the star fruit is widely grown throughout the state of Sao Paulo, it is lacking information on nutrition and fertilization effects on rootstocks star fruit in literature. The study aimed to evaluate plant growth and how much $\mathrm{Zn}$ accumulates in star fruit rootstocks subjected to different doses of zinc. The study was conducted between the months of September 2012 and February 2013, on a commercial seedling production nursery, located in Taquaritinga, SP. A randomized block experimental design was used consisting of five doses of zinc: zero, 2.0; 4.0; 6.0 and $8.0 \mathrm{mg} \mathrm{dm}^{-3}$ of $\mathrm{Zn}$. There were four repetitions and three plants per plot. The age of the rootstocks used in the experiment were one year and two months old and were grown in polyethylene bags, with pine bark as substrate. At 170 days after administering the zinc, the plant height, stem diameter, number of leaves, the dry weight of the shoot, roots and total dry weight were recorded. The zinc content in the roots and shoots was determined, following a calculation of the accumulation of $\mathrm{Zn}$ in different parts of the plant. Zinc influenced the plant height, stem diameter, leaf emergence and accumulation of dry matter of shoots, roots and total. Found that the greatest development of star fruit rootstocks was associated with the dose between 3.1 and $3.8 \mathrm{mg} \mathrm{dm}^{-3}$ of Zn. High doses of zinc impair the growth and accumulation of the micronutrient in star fruit rootstocks.
\end{abstract}

Index terms: Averrhoa carambola L., micronutrient, mineral nutrition.

\footnotetext{
${ }^{1}$ (Trabalho 206-14). Recebido em:18-07-2014. Aceito para publicação em: 26-01-2015.Parte da Dissertação de Mestrado do primeiro autor.

${ }^{2}$ Doutorando em Fitotecnia, Universidade Federal de Viçosa/UFV. Av. Peter Henry Holfs, s/n, CEP 36570-000, Viçosa-MG. E-mail: limanetoagro@hotmail.com

${ }^{3}$ Professor Convidado Université Laval. Canadá - E-mail: natale@fsaa.ulaval.ca

${ }^{4}$ Doutoranda em Agronomia, Universidade Estadual Paulista/Unesp. Rua Monção, 226, CEP 15385-000, Ilha Solteira-SP. E-mail: vivianemodesto@hotmail.com
} 


\section{INTRODUÇ̃̃O}

A produção de porta-enxertos e, posteriormente, de mudas de caramboleira, com estado nutricional adequado, é um dos fatores primordiais para o sucesso na exploração do pomar, podendo influenciar na precocidade de produção e refletir no retorno econômico do capital investido pelo fruticultor (ROZANE et al., 2011a; ROZANE et al., 2013).

O uso agronômico do zinco $(\mathrm{Zn})$ na produção de mudas pode favorecer a obtenção de plantas vigorosas e bem nutridas, quando este é aplicado em doses adequadas. A quantidade de $\mathrm{Zn}$ aplicada por muda é muito pequena, o que confere alta relação custo/benefício, com maior sustentabilidade nos sistemas de produção (NATALE et al., 2004).

O Zn é um elemento essencial a todos os vegetais, por participar diretamente da síntese do aminoácido triptofano e ser precursor do ácido indolacético (AIA), fitormônio relacionado ao crescimento e alongamento celular, além da síntese de proteínas (MARSCHNER, 1995; SADEGHZADEH, 2013). Faz parte da composição de inúmeras enzimas, além de manter a integridade estrutural da membrana celular (HANSCH; MENDEL, 2009).

A deficiência de $\mathrm{Zn}$ manifesta-se em folhas novas com sintomas moderados, como a clorose e folhas menores, até à forma mais intensa, quando o crescimento e a produção da planta são comprometidos devido à formação de roseta, ou seja, o alongamento dos internódios é reduzido, fazendo com que as folhas de vários internódios fiquem muito próximas umas das outras e no mesmo plano (EPSTEIN; BLOOM, 2006; MALAVOLTA et al., 1997).

As doses de macro e, especialmente, de micronutrientes para a adubação de mudas de espécies frutíferas são, em geral, definidas de forma pouco precisa ou mesmo empírica (CORRÊA et al., 2005). Alguns trabalhos têm mostrado que a adubação com Zn em frutíferas, como goiabeira (NATALE et al., 2002), maracujazeiro (NATALE et al., 2004; LIMA et al., 2007) e pinheira (GUIMARÃES et al., 2010), favorece o crescimento das mudas.

A deficiência de micronutrientes em uma cultura pode ocasionar desequilíbrios no metabolismo vegetal, tornando as plantas mais sensíveis a pragas e doenças, proporcionando, desta forma, elevação nos custos de produção. O estado nutricional da planta interfere no acúmulo de $\mathrm{Zn}$ nas folhas. Em plantas deficientes em $\mathrm{Zn}$, a mobilidade desse nutriente torna-se bem menor (LONERAGAN et al., 1987), acumulando-se preferencialmente em folhas mais velhas, e nessas condições não há acúmulo em tecidos jovens.

Apesar da importância do Zn para as culturas em geral, na literatura, há poucas informações sobre a utilização desse micronutriente na produção de porta-enxertos de caramboleira. Diante disso, o trabalho teve como objetivo avaliar o crescimento das plantas e o acúmulo de $\mathrm{Zn}$ em porta-enxertos de caramboleira submetidos a diferentes doses de zinco.

\section{MATERIAL E MÉTODOS}

O experimento foi realizado de setembro de 2012 a fevereiro de 2013, em um viveiro comercial de produção de mudas, situado no Sítio São João, município de Taquaritinga-SP, com coordenadas geográficas de $21^{\circ} 44^{\prime}$ de latitude sul e $48^{\circ} 29^{\prime}$ de longitude oeste, com altitude de $512 \mathrm{~m}$. O clima da região é classificado, segundo Köppen, como Cwa, subtropical com chuvas de verão e inverno relativamente seco.

Os porta-enxertos de caramboleira (Averrhoa carambola L.) utilizados no experimento tinham um ano e dois meses de idade e foram obtidos por propagação de sementes. Antes da aplicação dos tratamentos, foram separados, de forma aleatória, dois porta-enxertos do mesmo lote, determinandose suas características biológicas e, em seguida, separou-se em raízes e parte aérea, que foram secas em estufa a $65^{\circ} \mathrm{C}$. Em seguida, o material foi analisado para a determinação da concentração inicial de nutrientes.

Os porta-enxertos selecionados apresentavam as seguintes características: altura média $(59,3 \pm$ $0,2 \mathrm{~cm})$; diâmetro médio do caule $(4,8 \pm 0,2 \mathrm{~mm})$; número médio de folhas $(11 \pm 1)$; massa seca da parte aérea $(4,9 \pm 0,5 \mathrm{~g})$ e massa seca das raízes $(7,8 \pm 1,1$ g). A concentração inicial de nutrientes na parte aérea dos porta-enxertos, antes da aplicação do zinco, era a seguinte: $\mathrm{N}=6,8 ; \mathrm{P}=1,9 ; \mathrm{K}=6,0 ; \mathrm{Ca}=6,5 ; \mathrm{Mg}=$ 2,7; $\mathrm{S}=0,9 \mathrm{~g} \mathrm{~kg}^{-1}$, respectivamente, e $\mathrm{B}=25 ; \mathrm{Cu}=4$; $\mathrm{Fe}=29 ; \mathrm{Mn}=17 ; \mathrm{Zn}=49 \mathrm{mg} \mathrm{kg}^{-1}$, respectivamente. Nas raízes, a concentração de nutrientes era: $\mathrm{N}=4,0$; $\mathrm{P}=1,6 ; \mathrm{K}=3,6 ; \mathrm{Ca}=1,9 ; \mathrm{Mg}=1,7 ; \mathrm{S}=0,4 \mathrm{~g} \mathrm{~kg}^{-1}$, respectivamente, e $\mathrm{B}=10 ; \mathrm{Cu}=7 ; \mathrm{Fe}=119 ; \mathrm{Mn}=$ 9; $\mathrm{Zn}=26 \mathrm{mg} \mathrm{kg}^{-1}$, respectivamente.

Os porta-enxertos foram cultivados em sacos de polietileno $(18 \times 30 \mathrm{~cm})$ com volume de $2 \mathrm{dm}^{3}$, contendo substrato à base de casca de pínus $\left(\right.$ Plantmax $\left.^{\circledR}\right)$, e estes, colocados sobre bancadas sem espaçamento entre si. Os resultados da análise química do substrato, realizada no Instituto Agronômico de Campinas, encontram-se na Tabela 1. $\mathrm{O}$ delineamento experimental foi o em 
blocos casualizados, com cinco tratamentos, quatro repetições e três plantas por parcela, sendo um portaenxerto por recipiente de $2 \mathrm{dm}^{3}$. Os tratamentos consistiram em cinco doses de $\mathrm{Zn}\left(\mathrm{D}_{0}=\right.$ zero de $\mathrm{Zn} ; \mathrm{D}_{1}=2 ; \mathrm{D}_{2}=4 ; \mathrm{D}_{3}=6$; e $\mathrm{D}_{4}=8 \mathrm{mg} \mathrm{dm}^{-3} \mathrm{de}$ $\mathrm{Zn}$ ), que correspondiam a $0 ; 18,2 ; 36,4 ; 54,5$ e 72,7 $\mathrm{mg}$ de sulfato de zinco $\left(\mathrm{ZnSO}_{4} \cdot 7 \mathrm{H}_{2} \mathrm{O}\right)$ por unidade experimental, aplicadas superficialmente sobre o substrato. As doses foram baseadas nas mesmas utilizadas por Natale et al. (2002) para mudas de goiabeira.

Os porta-enxertos foram irrigados com água de poço semiartesiano, por sistema de microaspersão, acionado diariamente, de forma a manter a umidade próxima a $60 \%$ da capacidade de retenção do substrato. Para diminuir a alta incidência de luz solar, bem como a alta evapotranspiração, o viveiro foi coberto com tela de polipropileno com $30 \%$ de sombreamento.

No período precedente ao experimento (um ano e dois meses), foram realizadas três adubações com a fórmula 8-28-16 de N- $\mathrm{P}_{2} \mathrm{O}_{5}-\mathrm{K}_{2} \mathrm{O}$, aplicando-se $1 \mathrm{~g}$ planta $^{-1} \mathrm{em}$ cada adubação. A primeira adubação foi realizada trinta dias após a emergência, e as demais, espaçadas a cada sessenta dias. Durante a condução da pesquisa, realizaram-se mais duas adubações com a fórmula 10-10-10 de $\mathrm{N}-\mathrm{P}_{2} \mathrm{O}_{5}-\mathrm{K}_{2} \mathrm{O}$, de $1 \mathrm{~g}$ planta $^{-1}$, sendo a primeira realizada após a aplicação do zinco, e a segunda, sessenta dias após a primeira. A eliminação das ervas daninhas foi realizada de forma manual, e o controle de pragas e doenças, e todas as práticas culturais necessárias foram feitas por funcionários do viveiro. Essas práticas seguiram os mesmos critérios utilizados para a produção comercial de mudas das diversas espécies ali cultivadas.

Aos 170 dias após a aplicação dos tratamentos, época em que os porta-enxertos estavam aptos a ser enxertados, tanto por borbulhia como por garfagem, avaliaram-se: a altura (do colo da planta até a inserção da última folha), o diâmetro do caule (avaliado com paquímetro digital a $15 \mathrm{~cm}$ do colo das mudas) e o número de folhas.

As plantas foram coletadas e separadas em parte aérea e raízes, lavadas inicialmente com água destilada, em seguida com detergente neutro, na concentração de $0,1 \%$, depois com solução de $\mathrm{HCl}$, na concentração de $3 \%$ em volume e, por último, com água destilada e deionizada, conforme procederam Hernandes et al. (2011). Após a lavagem, o material foi seco em estufa com circulação forçada de ar, a $65^{\circ}$ $\mathrm{C}$, até massa constante $\mathrm{e}$, posteriormente, pesado para a obtenção da massa seca de cada parte. O material foi triturado em moinho tipo Wiley e analisado para a determinação da concentração de zinco na parte aérea e nas raízes, seguindo a metodologia de Bataglia et al. (1983).

O acúmulo (A) de Zn na parte aérea, nas raízes e na planta inteira (raízes + parte aérea) foi calculado pela expressão:

$\mathrm{A}=[\mathrm{MSPA}$ ou MSR $(\mathrm{g}) \mathrm{x}$ teor do elemento $\left.\left(\mathrm{mg} \mathrm{kg}^{-1}\right)\right] / 1.000$

em que: MSPA corresponde à massa seca da parte aérea; e MSR à massa seca das raízes.

A quantidade total de $\mathrm{Zn}$ acumulada na planta inteira foi calculada pelo somatório das quantidades acumuladas na parte aérea e nas raízes.

Os resultados obtidos foram submetidos à análise de variância e análise de regressão polinomial, com o auxílio do programa estatístico SISVAR (FERREIRA, 2011).

\section{RESULTADOS E DISCUSSÃO}

A altura dos porta-enxertos de caramboleira foi influenciada pelas doses de $\mathrm{Zn}$ aplicadas ao substrato (Figura 1). Pelo estudo da regressão, a maior altura das plantas $(108,8 \mathrm{~cm})$ foi obtida na dose máxima estimada de $3,5 \mathrm{mg} \mathrm{dm}^{-3} \mathrm{de} \mathrm{Zn}$. Doses maiores que esta promoveram menor crescimento dos porta-enxertos de caramboleira, porém sem sintomas de toxidez que, segundo Malavolta et al. (1997), caracteriza-se por clorose generalizada com pigmentos pardo-avermelhados em folhas novas.

Esses resultados estão de acordo com os obtidos por Natale et al. (2002), que verificaram máxima altura de mudas de goiabeira com $2,5 \mathrm{mg}$ $\mathrm{dm}^{-3}$ de $\mathrm{Zn}$ e redução do crescimento em doses maiores. Para o mamoeiro, Corrêa et al. (2005) verificaram que doses superiores a $1,6 \mathrm{mg} \mathrm{dm}^{-3} \mathrm{de}$ Zn provocaram redução no crescimento de mudas. Lima et al. (2007) verificaram que a máxima altura das mudas de maracujazeiro foi atingida com $10 \mathrm{mg} \mathrm{dm}^{-3}$ de $\mathrm{Zn}$. As diferentes doses máximas para o crescimento demonstram que as frutíferas apresentam exigências distintas em relação ao zinco.

A maior altura das caramboleiras, na dose de $3,5 \mathrm{mg} \mathrm{dm}^{-3} \mathrm{de} \mathrm{Zn}$, pode ser atribuída à sua ação como componente de vários sistemas enzimáticos que regulam diversas atividades bioquímicas das plantas, sendo parte específica do metabolismo de proteínas e necessário na formação de auxinas, fitormônios de crescimento (EPSTEIN; BLOOM, 2006).

$\mathrm{Na}$ avaliação da produção de mudas de caramboleira enxertadas, cultivadas em solução nutritiva, Rozane et al. (2011a) verificaram que 
as plantas atingiram $127 \mathrm{~cm}$ aos 308 dias de idade. Entretanto, deve-se levar em consideração que as condições de cultivo são diferentes. Em geral, aumento na velocidade de crescimento, desenvolvimento e precocidade de produção é verificado em cultivos em soluções nutritivas, por permitir melhor controle das proporções dos nutrientes, necessários ao crescimento vegetal (ROZANE et al., 2011b).

A adubação com zinco promoveu aumento do diâmetro caulinar dos porta-enxertos de caramboleira até à dose máxima de $3,8 \mathrm{mg} \mathrm{dm}^{-3} \mathrm{de} \mathrm{Zn}$, atingindo o diâmetro máximo de 7,5 mm (Figura 2). Esse valor é superior aos $6 \mathrm{~mm}$ considerados necessários para a realização da enxertia em porta-enxertos de caramboleira (ROZANE et al., 2011a; ROZANE et al., 2013). De acordo com Malavolta et al. (1997), o Zn, atua na síntese de auxina, estimulando o desenvolvimento e o alongamento das partes jovens da planta. $\mathrm{O}$ micronutriente, quando aplicado em doses superiores a $3,8 \mathrm{mg} \mathrm{dm}^{-3}$ de $\mathrm{Zn}$ reduziu o diâmetro caulinar dos porta-enxertos, o que indica que o excesso de $\mathrm{Zn}$ foi prejudicial ao crescimento. $\mathrm{O} \mathrm{Zn}$, quando em excesso, inibe a absorção de outros micronutrientes metálicos como $\mathrm{Fe}, \mathrm{Cu}$ e $\mathrm{Mn}$, em virtude de os mesmos serem íons catiônicos e possuírem propriedades químicas semelhantes (MARSCHNER, 1995; MALAVOLTA et al., 1997).

Quando utilizado na adubação de mudas de maracujazeiro-amarelo, o $\mathrm{Zn}$ proporcionou aumento no diâmetro caulinar das plantas até à dose máxima de 4,8 $\mathrm{mg} \mathrm{dm}^{-3}$ de Zn (NATALE et al., 2004). Porém, Corrêa et al. (2005) não verificaram resposta para a mesma variável em mudas de mamoeiro, utilizando doses de até $6 \mathrm{mg} \mathrm{dm}^{-3}$ de $\mathrm{Zn}$.

A emissão de folhas foi influenciada pelas doses de Zn aplicadas (Figura 3). Pelos resultados, verifica-se que o maior número de folhas $(37,8)$ foi obtido com a dose máxima de $3,8 \mathrm{mg} \mathrm{dm}^{-3}$ de $\mathrm{Zn}$. Os resultados estão de acordo com os obtidos por Guimarães et al. (2010) que, ao avaliarem a aplicação de doses de sulfato de zinco na produção de mudas de pinheira (Annona squamosa L.), verificaram que o incremento das doses de $\mathrm{Zn}$ proporcionou aumento do número de folhas nas plantas. Esse resultado difere do observado por Corrêa et al. (2002), ao constatarem que o zinco não influenciou sobre o número de folhas de mudas de aceroleira. Martinez et al. (2011), avaliando 14 progênies de cafeeiro cultivadas em solução nutritiva com duas concentrações de zinco, verificaram que o $\mathrm{Zn}$ estimulou a emissão de folhas de algumas progênies, entretanto reduziu em outras.

Com a elevação das doses de 3,8 para 6 e
$8 \mathrm{mg} \mathrm{dm}^{-3}$ de $\mathrm{Zn}$, verificou-se menor produção de folhas, 6,6 e 24,6\%, respectivamente. Tais resultados indicam a necessidade de cautela no que diz respeito à adubação com zinco para a produção de portaenxertos dessa frutífera, mostrando que existe um estreito limite entre a deficiência e a toxidez por Zn na planta (MALAVOLTA et al., 1997; MARSCHNER, 1995).

As doses de $\mathrm{Zn}$ influenciaram no acúmulo de massa seca da parte aérea dos porta-enxertos de caramboleira (Figura 4). A massa seca da parte aérea

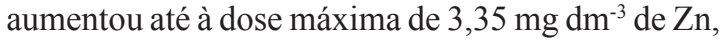
atingindo o valor máximo de 24,5 g. Doses maiores reduziram em até $18,8 \%$ o acúmulo de massa seca da parte aérea dos porta-enxertos. Esse comportamento foi verificado, também, por Guimarães et al. (2010) que, avaliando doses de sulfato de zinco na produção de mudas de pinheira, observaram maior acúmulo de massa seca da parte aérea com o incremento das doses de zinco; entretanto, doses superiores a 0,27 $\mathrm{mg} \mathrm{dm}^{-3}$ de sulfato de zinco provocaram redução na produção de massa seca.

A explicação para a redução na produção de massa seca em plantas com excesso de Zn é que, no xilema, acumulam-se tampões "plugs" contendo o elemento, os quais dificultam a ascensão da seiva bruta, além de interferir no metabolismo de carboidratos, inibindo o transporte de assimilados (MALAVOLTA et al., 1997).

Respostas positivas da utilização do zinco na produção de mudas também foram obtidas por Natale et al. (2004), ao avaliarem o uso desse micronutriente na produção de mudas de maracujazeiro. Os autores verificaram que houve aumento na produção de massa seca da parte aérea com o incremento das doses de zinco até a dose máxima de $5 \mathrm{mg} \mathrm{dm}^{-3} \mathrm{de}$ $\mathrm{Zn}$, enquanto doses maiores promoveram redução da produção de massa seca.

A produção de massa seca das raízes apresentou comportamento quadrático, sendo a dose estimada de $3,1 \mathrm{mg} \mathrm{dm}^{-3}$ de $\mathrm{Zn}$ a que promoveu maior acúmulo de massa seca do sistema radicular dos porta-enxertos de caramboleira (Figura 5). Entretanto, na maior dose de zinco $\left(8 \mathrm{mg} \mathrm{dm}^{-3} \mathrm{de} \mathrm{Zn}\right)$, houve redução de 16,2\% no acúmulo de massa seca. Esses resultados estão de acordo com os de Natale et al. (2002), que observaram redução no acúmulo de massa seca das raízes em mudas de goiabeiras que receberam elevadas doses de zinco. Porém, Fernandes et al. (2003) verificaram, em mudas de cupuaçuzeiro, que a massa seca das raízes, bem como da parte aérea aumentaram linearmente até a dose de $10 \mathrm{mg} \mathrm{dm}^{-3}$ de $\mathrm{Zn}$. Esses resultados indicam que as culturas respondem diferenciadamente ao zinco, 
conforme evidenciaram Pedrosa et al. (2013), ao avaliarem a resposta de mudas de 11 cultivares de cafeeiro, em duas concentrações de $\mathrm{Zn}$, verificando que ocorreu variação nas cultivares estudadas quanto à exigência e sensibilidade a doses elevadas de zinco.

A massa seca total dos porta-enxertos de caramboleira seguiu a mesma tendência da massa seca da parte aérea e das raízes (Figura 6). Pela análise de regressão, verifica-se que o zinco promoveu maior acúmulo de massa seca total, com valor máximo (46,3 g), na dose de $3,2 \mathrm{mg} \mathrm{dm}^{-3} \mathrm{de}$ $\mathrm{Zn}$. Essa dose é superior aos $2,0 \mathrm{mg} \mathrm{dm}^{-3} \mathrm{de} \mathrm{Zn}$ no substrato, que promoveu o máximo acúmulo de massa seca total por mudas de mamoeiro (CORRÊA et al., 2005). Porém, é inferior à dose de $5,0 \mathrm{mg} \mathrm{dm}^{-3}$ de Zn responsável pela maior produção de massa seca total, obtida na produção de mudas de maracujazeiro por Natale et al. (2004).

Nas maiores doses de Zn, observa-se redução na produção de massa seca total dos porta-enxertos de caramboleira. Isso pode ser justificado pelo fato de o excesso de $\mathrm{Zn}$ causar inibição do elongamento radicular, que é parâmetro característico de toxicidade de Zn (MARSCHNER, 1995). De acordo com Silva et al. (2010), o excesso de Zn geralmente induz a danos oxidativos várias espécies de plantas, dando início à peroxidação de lipídios e degradação de outros compostos vegetais. Esses fatores somados causam sintomas de toxicidade, que se refletem na redução de produção de massa seca da planta.
As doses de $\mathrm{Zn}$, aplicadas ao substrato, não afetaram o acúmulo do metal nas raízes; entretanto, influenciaram sobre o acúmulo de $\mathrm{Zn}$ na parte aérea e na planta inteira (Figura 7). Os acúmulos de Zn na parte aérea e na planta inteira (parte aérea + raízes) descreveram comportamento quadrático, indicando que as maiores doses não promoveram aumento em seu acúmulo.

O máximo acúmulo de Zn, na parte aérea e na planta inteira, foi obtido na dose de $4,7 \mathrm{mg} \mathrm{dm}^{-3} \mathrm{de}$ $\mathrm{Zn}$. Resultados semelhantes foram obtidos por Natale et al. (2004) em mudas de maracujazeiro, porém estes autores verificam resposta positiva do acúmulo de $\mathrm{Zn}$ nas raízes, o que não foi verificado nesta pesquisa. Em mudas de freijó (Cordia goeldiana Huber), Fernandes et al. (2007) verificaram que houve aumento linear no acúmulo de zinco nas folhas e nos caules com doses de até $10 \mathrm{mg} \mathrm{kg}^{-1}$ de $\mathrm{Zn}$.

O menor acúmulo de zinco na planta, em doses superiores a 4,7 $\mathrm{mg} \mathrm{dm}^{-3} \mathrm{de} \mathrm{Zn}$, é explicado porque doses elevadas de $\mathrm{Zn}$ podem reduzir o índice de translocação do elemento na planta, conforme verificado por Soares et al. (2001) e Natale et al. (2002) em mudas de eucalipto e goiabeira, respectivamente, e porque houve significativa redução da massa seca da parte aérea e da massa seca total da planta. Essa redução no índice de translocação ocorre porque, quando em excesso, o Zn acumula-se no xilema, reduzindo a ascensão da seiva bruta para a parte aérea das plantas (MALAVOLTA et al., 1997).

TABELA 1 - Análise química do substrato empregado no experimento.

\begin{tabular}{|c|c|c|c|c|c|c|c|c|c|}
\hline $\mathrm{pH}$ & $\mathrm{CE}$ & N-Nitrato & $P$ & $\mathrm{Cl}$ & $\mathrm{S}$ & $\mathrm{N}$-amônio & $\mathrm{K}$ & $\mathrm{Na}$ & $\mathrm{Ca}$ \\
\hline & $\mathrm{dS} \mathrm{m}^{-1}$ & - - - - - - - & $-\cdots$ & $-\cdots$ & - - - - & - - mg L $\mathrm{m}^{-1}$ & $\ldots$ & - - - - - - - & - - - - - - - - \\
\hline 5,9 & 1,6 & 106,7 & 11,0 & 20,2 & 84,3 & 2,5 & 108,9 & 24,8 & 148,3 \\
\hline $\mathrm{Mg}$ & B & $\mathrm{Cu}$ & $\mathrm{Fe}$ & $\mathrm{Mn}$ & $\mathrm{Zn}$ & Umidade & $\mathrm{N}$ & $\begin{array}{l}\text { Carbono } \\
\text { Orgânico }\end{array}$ & $\begin{array}{c}\text { Relação } \\
\mathrm{C} / \mathrm{N}\end{array}$ \\
\hline.-- & - - $^{-}$ & - - - - - - - & $\operatorname{lg~L}^{-1}$ & $-\cdots$ & $-\ldots$ & $\%$ & $-\cdots$ & $\mathrm{kg}^{-1}---$ & \\
\hline 50,6 & 0,3 & $<0,01$ & 0,03 & 0,02 & 0,02 & 58,5 & 8,3 & 366,5 & $44: 1$ \\
\hline
\end{tabular}

pH em água 1:1,5. Método de extração: 1:1,5 (Holanda). Métodos de determinação: N-(amoniacal e nitrato): destilação; K, Ca, Mg, $\mathrm{P}, \mathrm{S}, \mathrm{Cu}, \mathrm{Fe}, \mathrm{Mn}, \mathrm{Zn}$ : ICP-OES. Umidade $65^{\circ} \mathrm{C}$. Resultados para os teores totais de carbono e nitrogênio foram obtidos pelo novo equipamento de análise elementar de CNS (marca ELEMENTAR CNS).

Fonte: Instituto Agronômico de Campinas (IAC). 


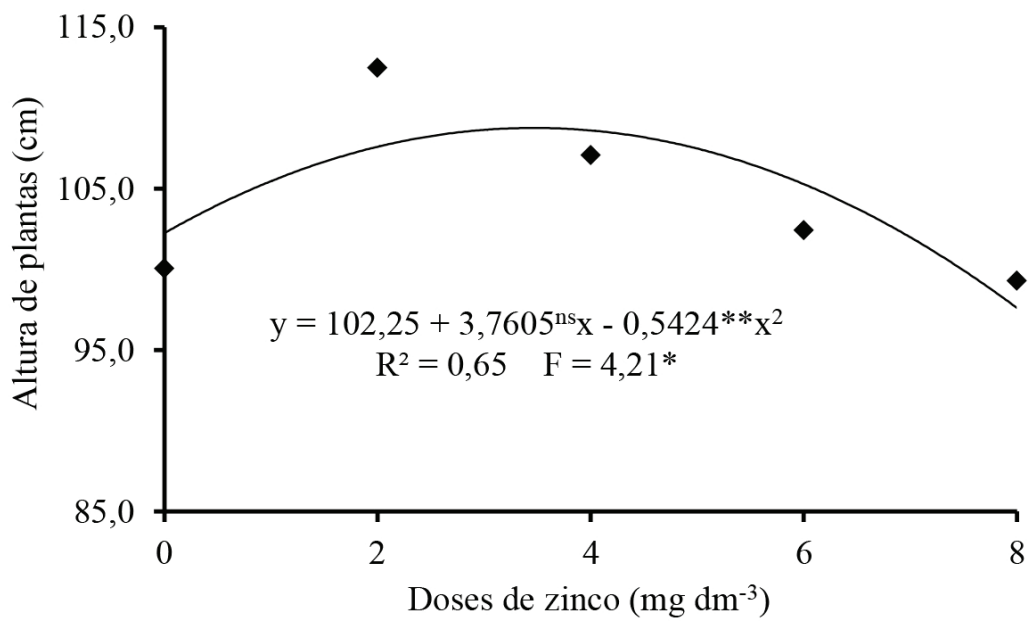

FIGURA 1 - Altura de porta-enxertos de caramboleira adubados com doses crescentes de zinco.

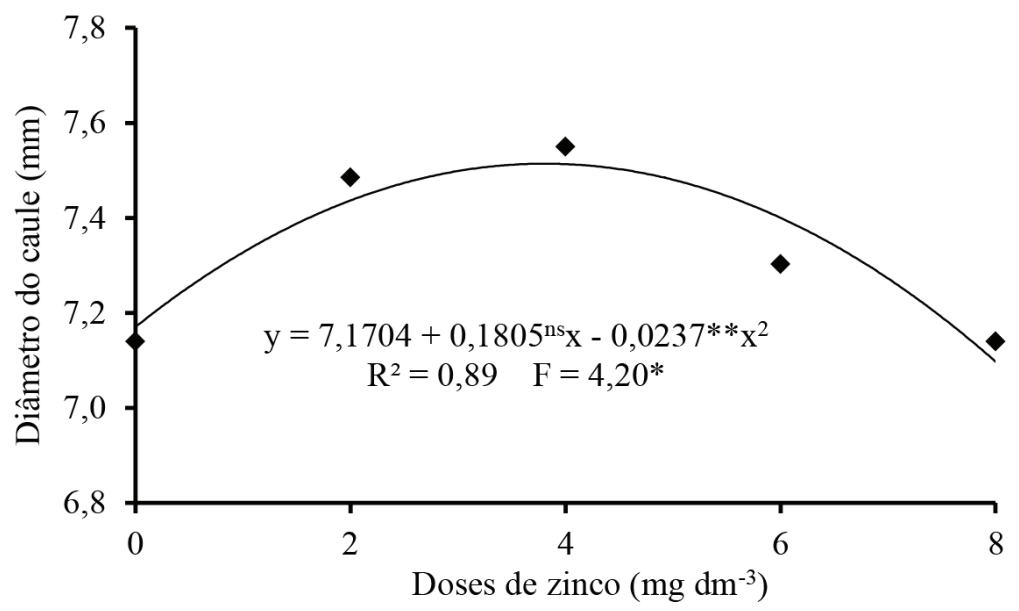

FIGURA 2 - Diâmetro do caule de porta-enxertos de caramboleira adubados com doses crescentes de zinco.

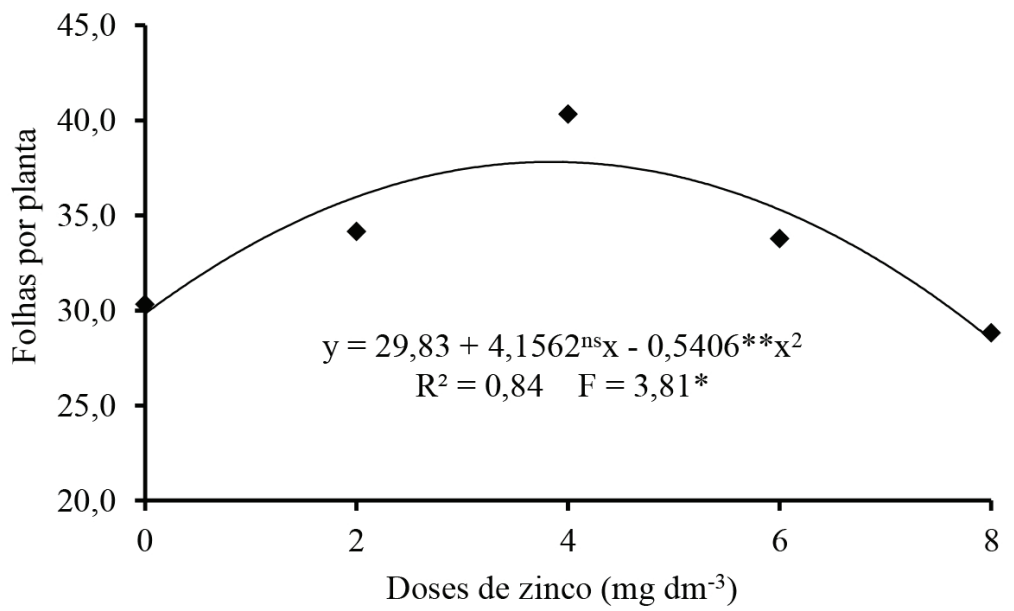

FIGURA 3 - Número de folhas nas mudas de caramboleira adubadas com doses crescentes de zinco. 


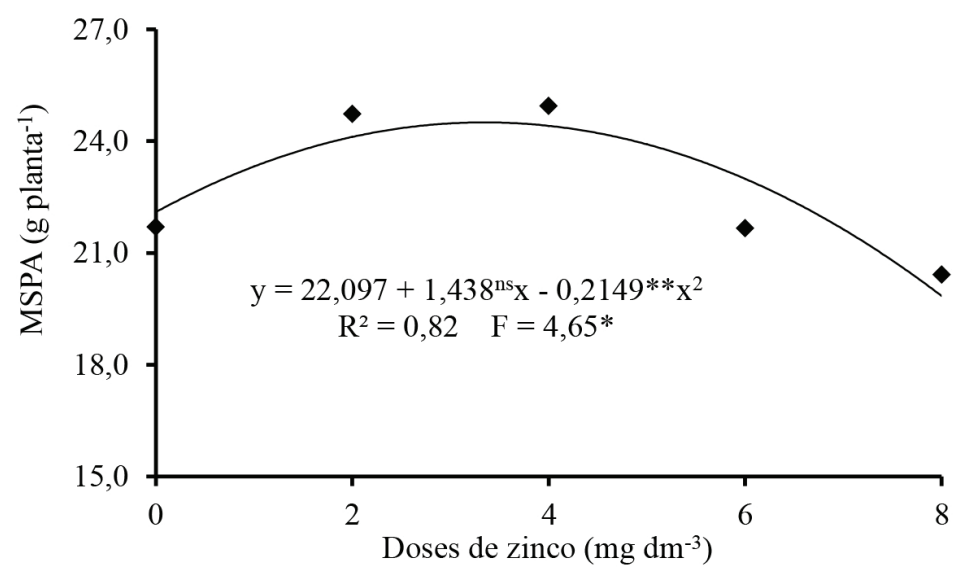

FIGURA 4 - Massa seca da parte aérea (MSPA) de porta-enxertos de caramboleira adubados com doses crescentes de zinco.

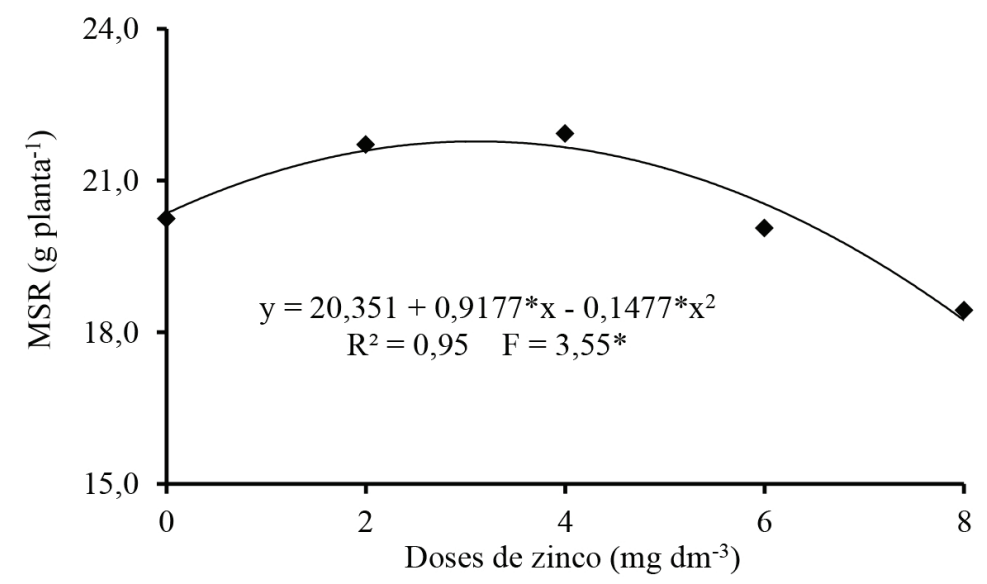

FIGURA 5 - Massa seca das raízes (MSR) de porta-enxertos de caramboleira adubados com doses crescentes de zinco.

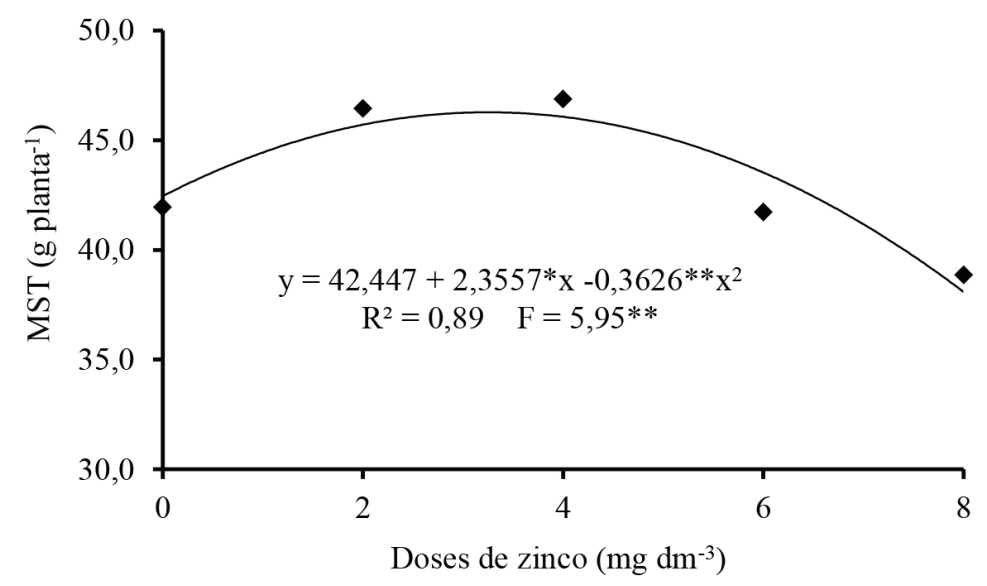

FIGURA 6 - Massa seca total (MST) de porta-enxertos de caramboleira adubados com doses crescentes de zinco. 


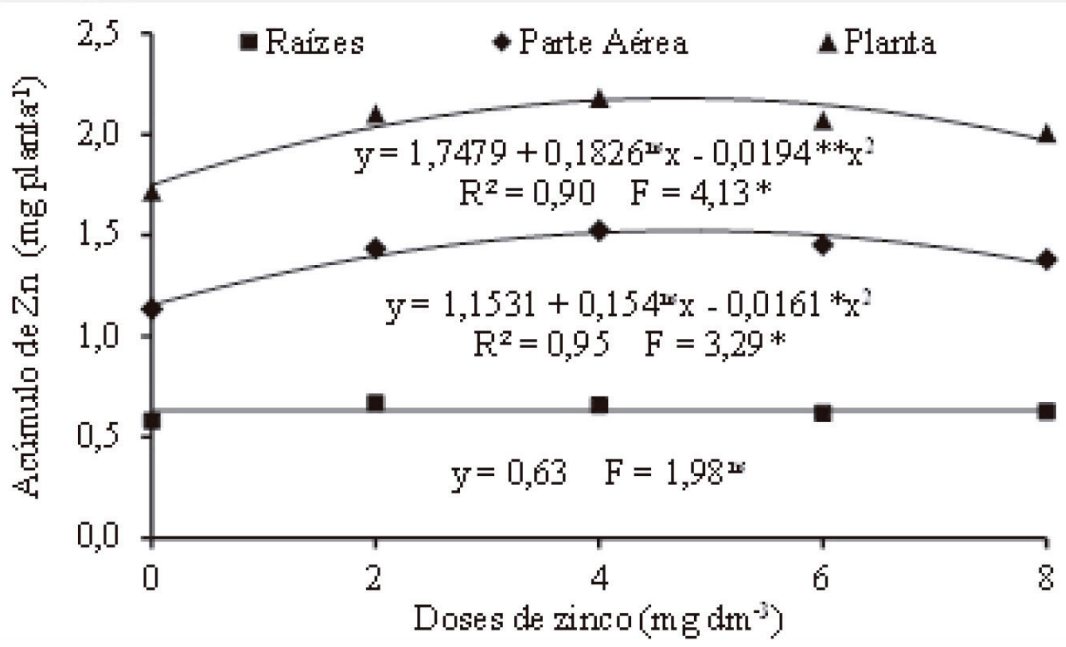

FIGURA 7 - Acúmulo de zinco nas raízes, na parte aérea e na planta inteira (raízes + parte aérea) de portaenxertos de caramboleira adubados com doses crescentes de zinco.

\section{CONCLUSÕES}

Os porta-enxertos de caramboleira respondem à aplicação de zinco no substrato.

O maior crescimento dos porta-enxertos está associado às doses entre 3,1 e 3,8 $\mathrm{mg} \mathrm{dm}^{-3} \mathrm{de} \mathrm{Zn}$.

O maior acúmulo de zinco na planta é obtido na dose de 4,7 $\mathrm{mg} \mathrm{dm}^{-3}$ de $\mathrm{Zn}$ de substrato.

Doses elevadas de zinco prejudicam o crescimento e o acúmulo do micronutriente nos porta-enxertos de caramboleira.

Considerando que, para os porta-enxertos, o parâmetro biológico diâmetro do caule é aquele que define o momento da enxertia, pode-se concluir que a dose adequada é 3,8 $\mathrm{mg} \mathrm{dm}^{-3}$ de $\mathrm{Zn}$.

\section{AGRADECIMENTOS}

Aos irmãos José Mauro da Silva, e João Mateus da Silva, pela colaboração e oportunidade de realização do experimento no viveiro de mudas do Sítio São João, em Taquaritinga-SP.

Ao professor Jairo Osvaldo Cazetta, por disponibilizar a casa de vegetação para realização de parte da pesquisa.

\section{REFERÊNCIAS}

BATAGLIA, O. C.; FURLANI, A. M. C.; TEIXEIRA, J. P. F. FURLANI, P. R. GALLO, J. R. Métodos de análise química de plantas. Campinas: Instituto Agronômico, 1983. 48p. (Boletim Técnico, 78)

CORRÊA, F. L. D. O.; SOUZA, C. A. S.; CARVALHO, J. G. D.; MENDONÇA, V. Fósforo e zinco no desenvolvimento de mudas de aceroleira. Revista Brasileira de Fruticultura, Jaboticabal, v. 24, n. 3, p. 793-796, 2002.

CORREAA, M. C. M.; NATALE, W.; PRADO, R. M. OLIVEIRA, I. V. M.; ALMEIDA, E. V. Adubação com zinco na formação de mudas de mamoeiro. Revista Caatinga, Mossoró, v. 18, n. 4, p. 245-250, 2005.

EPSTEIN, E.; BLOOM, A. J. Nutrição mineral de plantas: princípios e perspectivas. Londrina: Editora Planta, 2006. 403p.

FERNANDES, A. R.; CARVALHO, J. G. D.; MELO, P. C. Efeito do fósforo e zinco sobre o crescimento de mudas do cupuaçuzeiro (Theobroma grandiflorum Schum.). Cerne, Lavras, v. 9, n. 2, p. 221-230, 2003.

FERNANDES, A. R.; PAIVA, H. N.; CARVALHO, J. G.; MIRANDA, J. R. P. Crescimento e absorção de nutrientes por mudas de freijó (Cordia goeldiana Huber) em função de doses de fósforo e de zinco. Revista Árvore, Viçosa, MG, v. 31, n. 4, p. 599608, 2007. 
FERREIRA, D. F. Sisvar: a computer statistical analysis system. Ciência e Agrotecnologia, Lavras, v. 35, n. 6, p. 1039-1042, 2011.

GUIMARÃES, A. A.; MENDONÇA, V.; TOSTA, M. D. S.; DANTAS, D. D. J.; PAULA, Y. C. M.; RODRIGUES, G. S. O. Doses de sulfato de zinco na produção de mudas de pinheira. Revista Brasileira de Ciências Agrárias, Recife, v. 5, n. 2, p. 153-158, 2010.

HANSCH, R.; MENDEL, R. R. Physiological functions of mineral micronutrients $(\mathrm{Cu}, \mathrm{Zn}, \mathrm{Mn}, \mathrm{Fe}$, $\mathrm{Ni}, \mathrm{Mo}, \mathrm{B}, \mathrm{Cl}$ ). Current Opinion in Plant Biology, Cambridge, v.12, n. 3, p. 259-266, 2009.

HERNANDES, A.; CAZETTA, J. O.; NATALE, W.; ROZANE, D. E.; SOUZA, H. A.; ROMUALDO, L. M. Fracionamento de manganês acumulado nos tecidos de mudas de caramboleira. Revista Brasileira de Ciência do Solo, Viçosa, MG,v. 35, n. 5, p.1679-1685, 2011.

LIMA, R. A. F.; MENDONÇA, V.; TOSTA, M. S.; REIS, L. L.; BISCARO, G. A.; CHAGAS, E. A. Fósforo e zinco no crescimento de mudas de maracujazeiro-amarelo. Pesquisa Agropecuária Tropical, Goiânia, v. 37, n. 4, p. 251-256, 2007.

LONERAGAN, J. F.; KIRK, G. J.; WEBB, M. J. Translocation and function of zinc in roots. Journal of Plant Nutrition, Monticello, v.10, n. 9-16, p.12471254, 1987.

MALAVOLTA, E.; VITTI, G. C.; OLIVEIRA, S. A. Avaliação do estado nutricional das plantas: princípios e aplicações. Piracicaba: Potafós, 1997. $319 \mathrm{p}$.

MARSCHNER, H. Mineral nutrition of higher plants. $2^{\text {nd }}$ ed. San Diego: Academic, 1995. 902 p.

MARTINEZ, H. E. P.; ZABINI, A. V.; CRUZ, C. D.; PEREIRA, A. A.; FINGER, F. L. Differential tolerance to zinc deficiency in coffee-plant progenies. Journal of Plant Nutrition, Monticello, v. 34, n. 11, p.1654-1674, 2011. (1)

NATALE, W.; PRADO, R. M.; CORRÊA, M. C. M.; SILVA, M. A. C.; PEREIRA, L. Resposta de mudas de goiabeira à aplicação de zinco. Revista Brasileira de Fruticultura, Jaboticabal, v. 24, n. 3 , p. 770-773, 2002.
NATALE, W.; PRADO, R. M.; LEAL, R. M.; FRANCO, C. F. Efeitos da aplicação de zinco no desenvolvimento, no estado nutricional e na produção de matéria seca de mudas de maracujazeiro. Revista Brasileira de Fruticultura, Jaboticabal, v. 26, n. 2, p. 310-314, 2004.

PEDROSA, A. W.; MARTINEZ, H. E. P.; CRUZ, C. D.; DamatTA, F. M.; Clemente, J. M. Crescimento de cultivares de café em resposta a doses contrastantes de zinco. Coffee Science, Lavras, v. 8, n. 3, p. 295-305, 2013.

ROZANE, D. E.; PRADO, R. M.; NATALE, W.; FRANCO, C. F. Crescimento, teor e acúmulo de nutrientes em hipobiotos de caramboleiras, cultivados em diferentes soluções nutritivas. Revista Ceres, Viçosa, MG,v. 58, n. 3, p. 366-372, 2011 b.

ROZANE, D. E.; PRADO, R. M.; NATALE, W.; ROMUALDO, L. M.; FRANCO, C. F. Caracterização biométrica e acúmulo de nutrientes em porta-enxertos de caramboleira cultivada em solução nutritiva. Revista Ciência Agronômica, Fortaleza, v. 44, n. 3, p. 426-436, 2013.

ROZANE, D. E.; PRADO, R. M.; NATALE, W.; ROMUALDO, L. M.; SOUZA, H. A.; SILVA, S. H. M. G. Produção de mudas de caramboleiras 'B-10' e 'Golden Star': I - Parâmetros biológicos. Revista Brasileira de Fruticultura, Jaboticabal, v. 33, n. 4, p. 1300-1307, 2011a.

SADEGHZADEH, B. A review of zinc nutrition and plant breeding. Journal of soil science and plant nutrition, Temuco, v.13 n. 4, p. 905-927, 2013.

SILVA, T. M. R.; PRADO, R. M.; VALE, D. W.; AVALHÃES, C. C.; PUGA, A. P.; FONSECA, I. $\mathrm{M}$. Toxicidade do zinco em milheto cultivado em Latossolo Vermelho Distrófico. Revista Brasileira de Ciências Agrárias, Recife, v. 5, n. 3, p. 336-340, 2010.

SOARES, C. R. F. S.; GRAZZIOTTI, P. H.; SIQUEIRA, J. O.; CARVALHO, J. G.; MOREIRA, F. M. S. Toxidez de zinco no crescimento e nutrição de Eucalyptus maculata e Eucalyptus urophylla em solução nutritiva. Pesquisa Agropecuária Brasileira, Brasília, v. 36, n. 2, p.339-348, 2001. 